(1)

CrossMark

\title{
Is right heart catheterisation still a fundamental part of the follow-up assessment of pulmonary arterial hypertension? The argument against
}

\author{
Luke S. Howard \\ Affiliation: National Pulmonary Hypertension Service, Hammersmith Hospital, Imperial College Healthcare \\ NHS Trust, London, UK. \\ Correspondence: Luke S. Howard, National Pulmonary Hypertension Service, Hammersmith Hospital, \\ Imperial College Healthcare NHS Trust, Du Cane Road, London W12 OHS, UK. E-mail: l.howarddaimperial.ac.uk
}

@ERSpublications

Noninvasive assessment of pulmonary arterial hypertension is adequate to provide a risk assessment in the majority of cases. Patients need to be managed in high-volume, expert centres with access to invasive haemodynamics for selected use in follow-up http://ow.ly/lXrq30koXZV

Cite this article as: Howard LS. Is right heart catheterisation still a fundamental part of the follow-up assessment of pulmonary arterial hypertension? The argument against. Eur Respir J 2018; 52: 1800996 [https://doi.org/10.1183/13993003.00996-2018].

Right heart catheterisation (RHC) is arguably the most definitive and fundamental tool for diagnosing pulmonary hypertension, and is critical to distinguish between pre- and post-capillary pulmonary hypertension [1]. Without data obtained from a diagnostic RHC, pulmonary arterial hypertension (PAH) therapies should only be prescribed in the rarest of circumstances. It is the only test to provide accurate and precise information on the degree of elevation of the pulmonary vascular resistance (PVR), which is the primary pathophysiological process in PAH. For this reason, it has often acted as the primary end-point in phase II trials of pulmonary arterial vasodilator therapies for PAH.

While changes in PVR inform us about whether a drug is having an effect on the pulmonary circulation, it is well-known that prognosis is determined by the impact of the elevated PVR on the function of the right ventricle. Of course, RHC also provides information on right ventricular function, such as cardiac index, right atrial pressure (RAP) and mixed venous oxygen saturations, and these measurements are included in the European Respiratory Society (ERS)/European Society of Cardiology (ESC) risk stratification model (table 1) [1]. Indeed, the value of haemodynamic assessment at baseline and follow-up is well-documented $[2,3]$. Recently, the ERS/ESC low-risk criteria of RAP $<8 \mathrm{mmHg}$ and cardiac index $\geqslant 2.5 \mathrm{~L} \cdot \mathrm{min}^{-1} \cdot \mathrm{m}^{-2}$ have been shown to be independent prognosticators of transplant-free survival at first follow-up when considered in addition to functional class II and 6-min walking distance (6MWD) $>440 \mathrm{~m}$, using data from the French registry [4]. Moreover, when considering haemodyamics alone, stroke volume index (SVI) measured by RHC can provide even greater prognostic discrimination than cardiac index, likely because it is a more faithful measure of right ventricular function and unaffected by compensations in heart rate [5].

There are many other ways in which right ventricular function can be assessed, however, and the ERS/ESC model also lists echocardiography, serum brain natriuretic peptide (BNP) or N-terminal (NT)-proBNP, exercise capacity as assessed by 6MWD and cardiopulmonary exercise testing, and clinical assessment 
TABLE 1 Risk assessment in pulmonary arterial hypertension

\begin{tabular}{|c|c|c|c|}
\hline $\begin{array}{l}\text { Determinants of prognosis }{ }^{\#} \\
\text { (estimated 1-year mortality) }\end{array}$ & Low risk $<5 \%$ & Intermediate risk $5-10 \%$ & High risk $>10 \%$ \\
\hline Clinical signs of right heart failure & Absent & Absent & Present \\
\hline Progression of symptoms & No & Slow & Rapid \\
\hline Syncope & No & Occasional syncopefl & Repeated syncope ${ }^{+}$ \\
\hline WHO functional class & I, II & III & IV \\
\hline 6MWD m & $>440$ & $165-440$ & $<165$ \\
\hline Cardiopulmonary exercise testing & $\begin{array}{c}\text { Peak } V^{\mathrm{O}_{2}}>15 \mathrm{~mL} \cdot \mathrm{min} \cdot \mathrm{kg}^{-1} \\
{[>65 \% \text { pred }]} \\
V^{\prime} \mathrm{E} / \mathrm{V}^{\prime} \mathrm{CO}_{2} \text { slope }<36\end{array}$ & $\begin{array}{c}\text { Peak } V^{\prime} \mathrm{O}_{2} 11-15 \mathrm{~mL} \cdot \mathrm{min} \cdot \mathrm{kg}^{-1} \\
{[35-65 \% \text { pred] }} \\
V^{\prime} \mathrm{E} / \mathrm{VCO}_{2} \text { slope } 36-44.9\end{array}$ & $\begin{array}{c}\text { Peak } \mathrm{VO}_{2}<11 \mathrm{~mL} \cdot \mathrm{min} \cdot \mathrm{kg}^{-1} \\
{[<35 \% \text { pred }]} \\
V^{\prime} \mathrm{E} / \mathrm{VCO}_{2} \text { slope } \geqslant 45\end{array}$ \\
\hline NT-proBNP plasma levels ng.L-1 & $\begin{array}{c}\text { BNP }<50 \\
\text { NT-proBNP }<300\end{array}$ & $\begin{array}{c}\text { BNP 50-300 } \\
\text { NT-proBNP 300-1400 }\end{array}$ & $\begin{array}{c}\text { BNP > 300 } \\
\text { NT-proBNP }>1400\end{array}$ \\
\hline $\begin{array}{l}\text { Imaging (echocardiography, } \\
\text { CMR imaging) }\end{array}$ & $\begin{array}{l}\text { RA area }<18 \mathrm{~cm}^{2} \\
\text { No pericardial effusion }\end{array}$ & $\begin{array}{l}\text { RA area } 18-26 \mathrm{~cm}^{2} \\
\text { No or minimal } \\
\text { pericardial effusion }\end{array}$ & $\begin{array}{c}\text { RA area }>26 \mathrm{~cm}^{2} \\
\text { Pericardial effusion }\end{array}$ \\
\hline Haemodynamics & $\begin{array}{c}\mathrm{RAP}<8 \mathrm{mmHg} \\
\mathrm{Cl} \geqslant 2.5 \mathrm{~L} \cdot \mathrm{min}^{-1} \cdot \mathrm{m}^{-2} \\
\quad \mathrm{SvO}_{2}>65 \%\end{array}$ & $\begin{array}{c}\text { RAP } 8-14 \mathrm{mmHg} \\
\mathrm{CI} 2.0-2.4 \mathrm{~L} \cdot \mathrm{min}^{-1} \cdot \mathrm{m}^{-2} \\
\mathrm{SvO}_{2} 60-65 \%\end{array}$ & $\begin{array}{c}\mathrm{RAP}>14 \mathrm{mmHg} \\
\mathrm{Cl}<2.0 \mathrm{~L} \cdot \mathrm{min}^{-1} \cdot \mathrm{m}^{-2} \\
\mathrm{SvO}_{2}<60 \%\end{array}$ \\
\hline
\end{tabular}

WHO: World Health Organization; 6MWD: 6-min walking distance; NT: N-terminal; BNP: brain natriuretic peptide; CMR: cardiac magnetic resonance; $V^{\prime} \mathrm{O}_{2}$ : oxygen consumption; $V^{\prime} \mathrm{E}$ : minute ventilation; $V^{\prime} \mathrm{CO}_{2}$ : carbon dioxide production; RA: right atrial; $\mathrm{Cl}$ : cardiac index; Svo $\mathrm{c}_{2}$ mixed venous oxygen saturation. \#: most of the proposed variables and cut-off values are based on expert opinion. They may provide prognostic information and may be used to guide therapeutic decisions, but application to individual patients must be done carefully. One must also note that most of these variables have been validated mostly for idiopathic pulmonary arterial hypertension and the cut-off levels used above may not necessarily apply to other forms of pulmonary arterial hypertension. Furthermore, the use of approved therapies and their influence on the variables should be considered in the evaluation of the risk. ": occasional syncope during brisk or heavy exercise, or occasional orthostatic syncope in an otherwise stable patient. ${ }^{+}$: repeated episodes of syncope, even with little or regular physical activity. Reproduced from [1].

including functional class (table 1). The simplest objective measurement of all of these is arguably the BNP or NT-proBNP. When values of $<50$ or $<300 \mathrm{ng} \cdot \mathrm{L}^{-1}$, respectively, are considered in addition to RAP, cardiac index, 6MWD and functional class, in the same French registry dataset, the haemodynamic measurements no longer retain independent prognostic predictive capacity [4]. In other words, the BNP or NT-proBNP provides better predictive capacity than the RHC, when 6MWD and functional class assessment are also available. This is because BNP or NT-proBNP had a $98 \%$ sensitivity in this cohort for excluding patients with RAP $\geqslant 8 \mathrm{mmHg}$ and cardiac index $<2.5 \mathrm{~L} \cdot \mathrm{min}^{-1} / \mathrm{m}^{-2}$. While SVI may potentially be a better measurement than cardiac index, the hypothesis that it is better than or additive to BNP or NT-proBNP has not been tested.

It could be argued that knowledge of the RHC data in patients reported in the French registry somehow impacted upon survival by affecting treatment decisions and thus the only true way to determine if haemodynamics are not required to predict outcome is to undertake a study where they are not measured. No such study has been undertaken; however, two other registries, COMPERA [6] and the Swedish Registry (SPAHR) [7], have shown that applying the low-risk strata from the ERS/ESC model predicts good outcomes at follow-up and in both of these registries, only about a third of patients underwent RHC at follow-up assessment. This practice reflects that of expert centres.

Up to this point, we have only examined the issue of identifying patients at low risk of long term outcomes. Naturally, those not at low risk are at higher risk, but how well do invasive and noninvasive tools compare in discriminating between those at intermediate risk and those at high risk of death? The best information we have comes from the COMPERA registry [6], which demonstrates that the intermediate- and high-risk ERS/ESC criteria for 6MWD, BNP or NT-proBNP and functional class significantly outperform haemodynamics measured by RHC. Furthermore, when applying a different approach from that taken in the French registry, and averaging the number of low-, intermediate- and high-risk criteria in the COMPERA registry and SPAHR at follow-up, there is good separation of the groups in terms of long-term prognosis when only one third underwent RHC [6,7]. Moreover, the REVEAL risk calculator [8], which is a weighted score and was derived from a large US registry, gives us 
further insight into the added value of RHC measurements. Based on multivariate analysis, a PVR $<5$ Wood units and RAP $>20 \mathrm{mmHg}$ within the first year of diagnosis were able to refine the overall risk score by -1 or +1 out of a total score of 23 , which is evidently a relatively small component of the overall score.

These data are from large cohorts and to answer the question posed to us in this debate, we need to consider how follow-up data may be used in individual patients. Based on modern practice, most patients with $\mathrm{PAH}$ are typically started on dual oral combination therapy at diagnosis with an endothelin receptor antagonist and phosphodiesterase type 5 inhibitor; thus, the subsequent step in the decision-making process is already narrowed to parenteral prostanoids, oral prostanoids/IP3 receptor agonists, switching to soluble guanylate cyclase stimulators and when all other steps have been exhausted, referring for lung transplantation. More often than not, it may be clear what the most appropriate treatment approach might be; for example, where the patient is very stable, all the noninvasive markers align or where treatment options are limited either because the patient is already on maximal therapy. Where RHC may be applied is in the case of uncertainty, such as disagreement between noninvasive tests or where further risk stratification is needed in the intermediate risk category to assign the patient either into low or high risk. That said, there is still a potential role for other measures not discussed so far, such as cardiopulmonary exercise testing, echocardiography and potentially cardiac magnetic resonance imaging, before undertaking RHC. However, when treatment options are limited to binary decisions, it is hard to imagine that small adjustments to risk over and above noninvasive tools, when coupled with physician expertise and patient preference, will swing a decision; but clearly, there will be a minority of circumstances where this is the case. This ultimately highlights the need for patients to be managed in high-volume, expert centres where there is easy access to RHC and willingness to undertake it under circumstances when a criticial decision has to be made about timing of RHC as well as acting on the result.

Where does this leave RHC? The data we have so far suggest that noninvasive procedures can provide most of the information we need to risk-stratify patients and in real-world registries, that RHC can be used selectively. This has taken RHC away from a fundamental role in repeated (e.g. annual) assessments at follow-up, i.e. where it is performed in nearly all or even the majority of cases. If the argument were that we could do without RHC altogether in follow-up, then this would be absurd. The practice in our institution is perhaps somewhere in the middle, which is to undertake a full assessment of risk at baseline of all the measurements in the ERS/ESC model and then to repeat all measures, including RHC, at 36 months to provide the best pathophysiological phenotypic description of the patient following treatment in order to set the patient on the right course and provide a new baseline. We believe this to be the best standard of care from which deterioration can be measured at any point in the future, but routine, repeated RHC is not required unless noninvasive risk stratification fails to give a clear indication of disease status.

Finally, the French registry data do remind us of the powerful prognostic value of RHC when taken in isolation or with few other available parameters and also provide us with the important finding that SVI may have greater prognostic capacity than cardiac index. Perhaps this may appear in place of cardiac index in future iterations of the risk model? Whether it adds value in addition to a comprehensive noninvasive data collection, sufficient to make a clinically relevant, and not just statistically significant, difference in order to affect treatment decisions remains to be seen. However, if it does, then perhaps this can be gained using cardiac magnetic resonance imaging, but that, of course, is another debate.

Conflict of interest: None declared.

\section{References}

1 Galiè N, Humbert M, Vachiery JL, et al. 2015 ESC/ERS Guidelines for the diagnosis and treatment of pulmonary hypertension. Eur Respir J 2015; 46: 903-975.

2 Nickel N, Golpon H, Greer M, et al. The prognostic impact of follow-up assessments in patients with idiopathic pulmonary arterial hypertension. Eur Respir J 2012; 39: 589-596.

3 Humbert M, Sitbon O, Chaouat A, et al. Survival in patients with idiopathic, familial, and anorexigen-associated pulmonary arterial hypertension in the modern management era. Circulation 2010; 122: 156-163.

4 Weatherald J, Boucly A, Sahay S, et al. The low-risk profile in pulmonary arterial hypertension. Time for a paradigm shift to goal-oriented clinical trial endpoints? Am J Respir Crit Care Med 2018; 197: 860-868.

5 Weatherald J, Boucly A, Chemla D, et al. Prognostic value of follow-up hemodynamic variables after initial management in pulmonary arterial hypertension. Circulation 2018; 137: 693-704.

6 Hoeper MM, Kramer T, Pan Z, et al. Mortality in pulmonary arterial hypertension: prediction by the 2015 European pulmonary hypertension guidelines risk stratification model. Eur Respir J 2017; 50: 1700740.

7 Kylhammar D, Kjellström B, Hjalmarsson C, et al. A comprehensive risk stratification at early follow-up determines prognosis in pulmonary arterial hypertension. Eur Heart J 2017 in press [https://doi.org/10.1093/eurheartj/ehx257].

8 Benza R, Elliot C, Farber HW, et al. Updated risk score calculator for patients with pulmonary arterial hypertension (PAH) in the Registry to Evaluate Early and Long-Term PAH Disease Management (REVEAL). Am J Respir Crit Care Med 2017; 195: A6899. 